\title{
ONCHOCERCIASIS IN COMMUNITIES IN FOREST ZONE, SOUTH WEST NIGERIA: PREVALENCE AND DIAGNOSTIC METHOD FOR RAPID ASSESSMENT
}

\author{
"Adeyeba O.A., 'Adegoke, A.A. \\ 'Department of Medical Microbiology and Parasitology, College of Health Sciences, \\ Ladoke Akintola Univeristy of Technology, Osogbo, Nigeria
}

To determine the prevalence of onchocerciasis and diagnostic method for a rapid assessment of the disease in Iwo Local Government Area (LGA) of Osun State, Nigeria.

Method: the study area was randomly selected using lottery method. The study subjects are from all works of life of both sexes and not below the age of 10. Structured questionnaire was administered to obtain vital epidemiological information from study subjects. Skin snip as standard method of diagnosing onchocerciasis was done using method as described and was compared with other potential diagnostic indicators. The methods of sample analysis are described. Data were analysed by using correlation coefficient, Duncan multiple range test, and analysis of variance where appropriate.

Results: of the 240 subjects examined, $35.4 \%$ were skin snip positive. Whereas infection increases with age of subjects $(P<0.05)$, the difference in the infection among male and female subjects is not significant $(P>0.05)$. Of all the methods of diseases assessment, only nodule palpation method correlate weil with the standard diagnostic method - skin snip.

Conclusion: the merit of nodule palpation and criteria for the determination are discussed. Nodule palpation assessment method (NPAM) was recommended as an aiterhitive rapid assessment method of large scale surveillance of onchocerciasis in Nigeria. NPAM could be used for monitoring and evaluation of the current programme of mectizan distribution in the country.

\section{INTRODUCTION}

Onchocereiasis is a major public health problem in West Africa. Although the onchocerciasis control programme (OCP) in the Volta River Basin areas and Nigeria have reported success, the problem persists in neighbouring countries. In Nigeria, onchocerciasis is nation wide in terms of geographical spread and importance (1).

Although ochocrciasis has existed in Nigeria for centuries, it was not until 1908 that the first report was. published (2). Many authors $(1,3,4)$ had since contributed to the existing knowledge of its natural epidemicity. Inspite of this, the distribution of the infection and its vector in Nigeria are far reach than currently known. For several poorly accessible areas of high endemicity exist in different geographical locations of this country where numerous infected rural resident were unidentified, undiagnosed and untreated (4).

- The merits of the use ivermectin (mectizan) in the control of onchocerciasis are many, as many communities in Nigeria have benefited. The distribution of the mectizan is blindly guided by assumption based on previous knowledge of the disease in the country. The principle and procedure

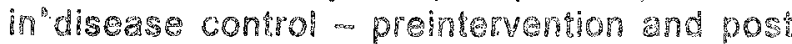

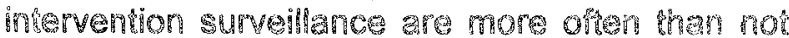

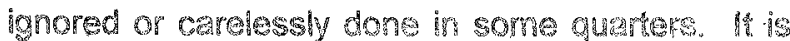

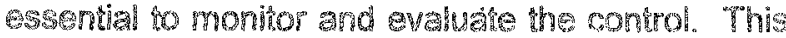

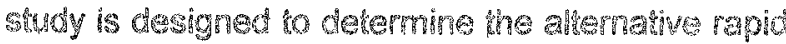

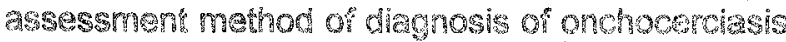

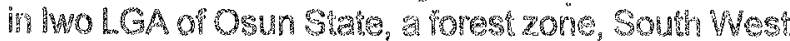

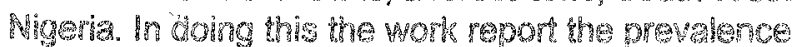
or onchocersiasis in the ares.

\section{MHTERALS AND METHODS}

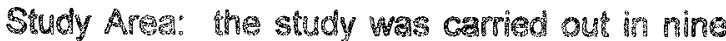
communises in Ho Local Govmment Area (LCA)

\section{*orrospopding Author}

of Osun State, Nigeria between November and December 1999. The study area is in the rain forest zone with a major river - Oba passing through. The major occupation of the people, which are predominantly Yoruba speaking is farming.

Sample selection method: the LGA was randomly selected from the 30 LGA in Osun State using lottery method. Nine villages were subsequently selected randomly. These villages were then paid advocacy visit to enhance success of the study in the area. The Local Health officials served as guides and helps.

Sample collection: in all, 240 subjects of both sexes whose age is not below 10 years old were enlisted. Skin snips and urine samples were aseptically collected from subjects using the method described by Basile (6). Care was taken in ensuring that blood did not contaminated sniped skin. Subjects were examined for the presence of leopard skin, nodules, such information on purities, excoriation, sex. age, occupation, history of infection were obtained by the administration of structured questionnaire.

Sample Analysis: Basically, samples were analysed using he methods described by basile et al (6).

Skin snip: Blood langer and razor were used to snip skin (1.5mm bite) from the illac crest ather suabsing with $70 \%$ alcohol. This wes placed in sulne proparation and later the aspirate was placed on microscope slide with cover slip appled and exmined under compound microscops. Counts of microfilarias (mi) were made and mf density was calculated by dividing the number of mf counted by 0.65 (the average weight of 49 skin smip specimen poted and weighed afer blotting dry on finter paper). Intensity of infection for each individual was calculated as the average of two snips divided by 0.65 as described by Sokal and Rohin (7). The community 
microfilarial load (CMFL) was determined by using the natural logarithm of the mean individual intensity plus 1 (i.e. $\log x+1$ ). The CMFL includes both positive and negative subjects.

Nodule assessment: each subject was palpated from head to toe using both hands with special attention to ribcage, iliac crest, greater trochanters, knees and scàpular for nodules.

Leopard skin/Depigmentation assessment: this was recorded as present or absent after examining the lower limb for the presence of characteristic depidgmentation on the skin.

Urine examination: Urine sample was collected in $50 \mathrm{ml}$ capacity bottle and allowed to stand for 2 hours to $7 \mathrm{hrs}$. the sediments were examined microscopically for the presence of $\mathrm{mf}$.

Degree of puritus: this was confirmed from subjects and reported as present or absent.

Excoriation: this obvious self-inflicted scratch marks explained by Basile (6) and reported as present or absent with special attention to trunk, buttocks and the lower limbs.

Data generated in each of the parametric methods were correlated with those of skin snip (the standard predictor of infection). The method that correlated with skin snip was deemed to be the method of choice is alternative on the field.

Data analysis: this was done using correlation coefficient, analysis of variance and Duncan multiple range test.

\section{RESULTS}

Prevalence on onchocerciasis in Iwo LGA

Table 1 shows the prevalence of onchocerciasis using sking snip method by sex and age of the 240 subjects examined, $35.4 \%$ were positive. Result shows that infection rate increases with age. The difference in infection rate between age group is statically significant $(P<0.05)$. The results also shows that more males than females are infected but eh difference is statistically insignificance $(P<0.05)$.

Prevalence of Onchocerciasis by village and method and of Assessment
Table 2 shows prevalence of onchocerciassis in each of the 9 villages by assessment method. Skin snip positivity shows that disease is unevenly distributed among the villages. Data reveals the intensity of infection (0.8-1.2) as reflected by community microfilaria load (CMFL) in the community.

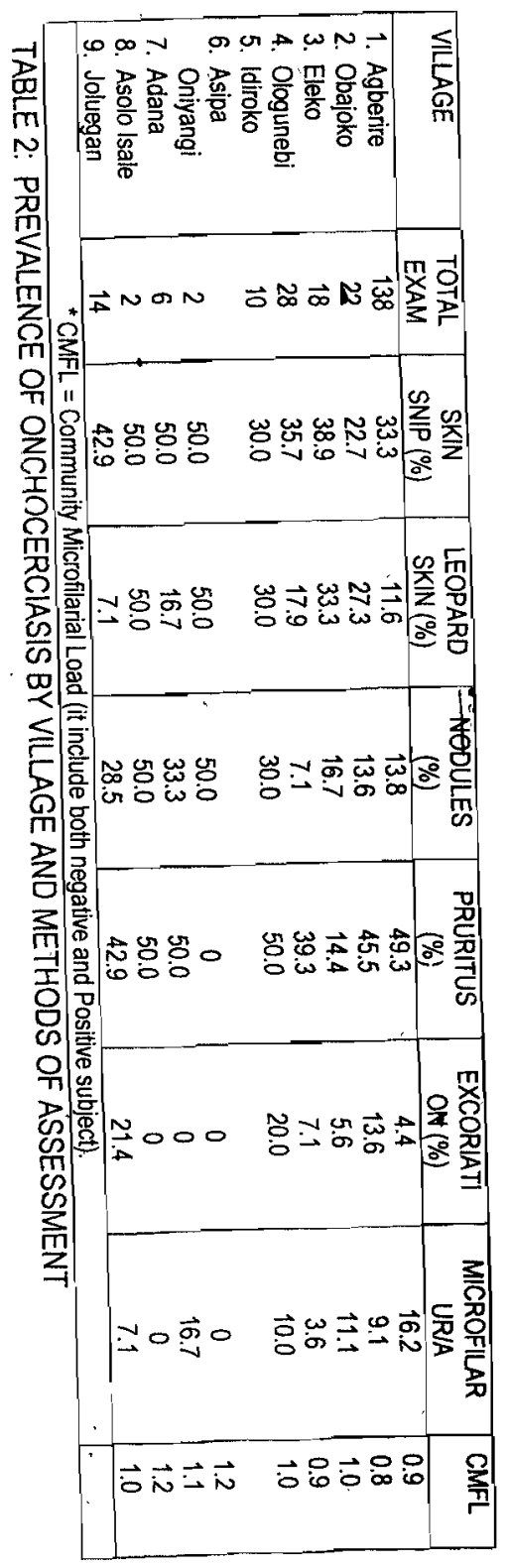

\begin{tabular}{|c|c|c|c|c|c|c|c|c|c|}
\hline $\mathrm{Age}$ & \multicolumn{3}{|c|}{ MALE } & \multicolumn{3}{|c|}{ FEMALE } & \multicolumn{3}{|c|}{ TOTAL } \\
\hline $\begin{array}{l}\text { Group } \\
\text { (Year) }\end{array}$ & $\begin{array}{l}\text { No. } \\
\text { Exam. }\end{array}$ & $\begin{array}{l}\text { No } \\
\text { Pos }\end{array}$ & $\begin{array}{l}\% \\
\text { Pos }\end{array}$ & $\begin{array}{l}\text { No: } \\
\text { Exam. }\end{array}$ & $\begin{array}{l}10 \\
\text { os }\end{array}$ & $\begin{array}{l}\% \\
\text { Pos }\end{array}$ & $\begin{array}{l}\text { No. } \\
\text { Exa }\end{array}$ & $\begin{array}{l}\text { No } \\
\text { Pos }\end{array}$ & $\begin{array}{l}\% \\
\text { Pos }\end{array}$ \\
\hline $10-20$ & 27 & 3 & 11.1 & 22 & 1 & 4.5 & 49 & 74 & -8.2 \\
\hline $21-30$ & 12 & 4 & 33.3 & 14 & 2 & 14.3 & 26 & 6 & 23.1 \\
\hline $31-40$ & 9 & 1 & 11.1 & 29 & 9 & 31.0 & 38 & 10 & 26.3 \\
\hline $41-50$ & 33 & 15 & 45.5 & 21 & 15 & 71.4 & 54 & 30 & 55.6 \\
\hline 51.60 & 21 & 10 & 47.6 & 15 & 5 & 33.3 & 36 & 15 & 41.7 \\
\hline$>60$ & 24 & 12 & 50 & 13 & 8 & 61.5 & 37 & 20 & 54.1 \\
\hline All & 126 & 45 & 35.7 & 114 & 40 & 35.1 & 240 & 85 & 35.4 \\
\hline
\end{tabular}

TABLE 1: PEEVALENCE OF ONCHOCERCIASIS USING SKIN SNIP POSITIVITY IN IWO LGA BY SEX AND AGE 
Mean and range values of study methods and correlation with skin snip and CMFL: Data in Table 3 show that skin snip and CMFL correlate. Nodule assessment also correlate most with both skin snip and CMFL $(P>0.05)$ though followed by Leopard skin (LS) which does not correlate with the former $(P<0.05)$. The other parametric methods do not correlate with the standard predictor method - skin snip.
The parametric assessment and correlation with skin snip and CMFL by village is shown in Table 4. there is varied correlation pattern of assessment method to the standard skin snip positivity in the villages. Generally nodules assessment correlates with both skin snip positivity and CMFL.

\begin{tabular}{|c|c|c|c|c|c|c|}
\hline METHODS & MEAN & RANGE & $\begin{array}{l}\text { SKINSNIP } \\
p \quad p\end{array}$ & $\begin{array}{l}\text { CMFL } \\
r \quad p\end{array}$ & & \\
\hline $\begin{array}{l}\text { Skin snip } \\
\text { Positivity (\%) } \\
\text { CMFL (mf/mg) } \\
\text { Leopard Skin }(\%) \\
\text { Nodules }(\%) \\
\text { Pruritus (\%) } \\
\text { Excoriation (\%) } \\
\text { Microfilarial (\%) }\end{array}$ & $\begin{array}{l}39.3 \\
1.01 \\
27.10 \\
27.0 \\
52.60 \\
12.02 \\
10.61 \\
\end{array}$ & $\begin{array}{l}22.7-50 \\
0.8-1.2 \\
7.1-50 \\
7.1-50 \\
39.3-94 \\
4.4-2.4 \\
36-16.7\end{array}$ & $\begin{array}{l}0.9010 \\
0.3289 \\
0.7447 \\
0.0892 \\
0.0030 \\
0.2810\end{array}$ & $\begin{array}{l}- \\
<0.0009 \\
0.3575 \\
0.1214 \\
0.8336 \\
0.09956 \\
0.5415\end{array}$ & $\begin{array}{l}0.9010 \\
-0.6226 \\
0.9249 \\
0.1527 \\
0.3079 \\
0.3570\end{array}$ & $\begin{array}{l}<0.0009 \\
- \\
0.0734 \\
<0.0004 \\
0.7181 \\
0.5528 \\
0.4319\end{array}$ \\
\hline
\end{tabular}

TAb6 3: MEALS AND RANGE VALUES OF STUDY METHODS AND CORRELATION WTH SKIN SNIP AND CMFL

\section{DISCUSSIQN}

Onchocerciasis a tissue parasitic disease is caused by the filarial worm of the Genus Onchocerca volvolus and transmitted by black flies of the genius Simulium (8). Several African countries have recognized the disease and have embarked on preparation for control (9).

This study has shown a prevalence rate of $35.4 \%$ and a low intensity rate of infection (CMFL) that is far less than what is typically reported from other regions of forest onchocerciasis $(10,11)$. The low prevalence of disease in Iwo LGA could be due to the control effort already put in place. Most of the study subjects have been treated or immunized with Mectizan. The different result is also party due to the difference in geographic area of study.

Many different criteria have been used for tefining the level nf endemicity of onchocerciasis in a population. According to Mcmahun et al (11), the onchocerciasis programme classified levels are sporadic, hypo, meso-or hyperendemic - on the basis of the standardized mf prevalence being $<10 \%$, $10-29 \%, 30-59 \%$ and $64 \%$ respectively. Therefore Iwo LGA is deemed to be classified as mesoendemic in view of the prevalence rate of $35.4 \%$. It has been shown that infection increases with age of subject in the area. This means that able - bodies men in their productive years are bound to be afflicted with the attendant dwindling fortune at old age. The pattern of infection distribution in this study conforms to other reports (6). The highest rate was found among age $41-50$ with $55.6 \%$. That gender factor has no effect on distribution pattern is an indication that there is no discriminatory infectionbased on sex as both sexes are equally vulnerable by reason of exposure to the bite of the vector. The low infection rate among certain age group in the area is largely due to in and out pattern of living in the area just as a student on vacation. It was discovered that majority of subjects in the age group with low infection rate are not permanent residents on the farmhouses. They merely come to the far for a brief period and return to the city. This predisposed them to infrequent bite by vector. There is a need to put in place a virile control programme in conformity with the principle and practice of disease control which component include .monitoring and evaluation through periodic epidemiological.survey.

Based on the analysis of large volumes of epidemiological data on onchocerciasis from West, Central and East African, it was recommended among other things that pigmentation of the skin and palpation for nodules may be used as alternative methods for community diagnosis of onchocerciasis (12).

Although the demonstration of skin snip for microfilarial is the most common and reliable, the procedure demand among them, and the use of a microscope, a razor blade or preferably a sclero punch and the availabilitv of trained personnel. Skin snipping is often frightening there by requiring persuasion and sometimes incentives to secure the cooperation of the villagers (1). The method is not acceptable for long scale mapping of onchocerciasis because the method is costly, time consuming and could introduce serious risk of transmitting agents such as human immunodeficiency virus and hepatitis virus $B$. Therefore the development of alternative method has become imperative. This study has shown that nodule palpation assessment method NPAM is an alternative rapid assessment method of diagnosing the disease. The NPAM has been shown to correlate well with skin snip method. This report accords well with the finding of some authors $(5,6,11,13)$. The cheering news of this methods is that all the disadvantages of the skin snip method are taken care of. Therefore NPAM is strongly recommended for monitoring and evaluation of the current control programme of mectizan distribution. 
This study has also shown that the use of pruritus and excoration may mislead diagnosis since different factors may be responsible for pruritus. For example, insect bite (other than that of Simullum) and reaction to some antigenic substances and also idiosyncrasy of individuals may provoke pruritus.

It has been shown that urine examination method is not sensitive as diagnosis could be missed even among individual whose skin snip is positive. These have been confirmed statistically as the method failed to correlate with the conventional skin snip.

In conclusion therefore, we recommend the use nodule palpation as a rapid predictor of onchocerciasis in large scale monitoring and evaluating the disease control programme.

Other methods of assessment of onchocerciasis are not recommended for use in the study area since they do not correlate well with the conventional standard method - skin snip. It is to be noted that the correlation pattern of the different assessment method to skin snip varies by village. For example, in one village the methods did correlate with skin snip (P>0.05), while others show confusing pattern. In essence, the method of choice is still NPAM which correlate at all times with skin snipping.

\section{REFERENCE}

1. Edungbola, L. D. Alabi, T. O., Oni O. A. Asaolu, S. O., Ogunbanji B. O. and Parakoyi, B. D: Leopard skin as "a rapid diagnostic idex for estimating the endemicity of African onchocerciasis. International J. Exid. 1987 16: $590-594$.

2. Obidigbo U: The state if onchocerciasis in some northern state of Nigeria. A comparative study of the situation in 1977 and 1981. Tropical Dis. Res. 1982. 1:29.

3. Wyatt, G. B: Onchocerciasis in Ibarapa, Western State. Nigeria Ann Trop Med. Parasital 1971. 65: $513-523$.

4. Edungbola. L. D.: The prevalence of onchocerciasis in Ile-Ire District (Ifelodun) Kwara State Nigeria. Trop Geog Med. 1982. 34231139.

5. Edungbola L. D.; Mwoke, B. E. B: Onwibri, 'C. O. E.; Akpa A. U.C. and Tayo - Mofe M: Selection of rapid assessment methods for community diagnosis of onchocerciasis in Nigeria. A recapitulation Nig. J. Parasitol. 1993.

6. Basile, K. Francis J. M. and Barnett $L_{1}$ : Evaluation of laternate methods of rapid assessment of endemicity of Ochocerca volvolus in communities southern Cameroon. Am J. Trop. Med. Hyg. 1995, $53(3): 243-247$

7. Sokal R. R. and Rohif J. P.: in Biometry 2nd́ Edn. Freeman and co New York 1981.

8. Murray D. D. and Mcgavin, $M$ : In "Onchocerciasis Manson tropical Diseases 12th Edn. Saunders Co. Ltd. 1996, p 1338.

9. Buck, A. A: Onchocerciasis, symptomotology pathology and diagnosis. WHO Geneva 1974.
10. Zimmerman, P: Dadzie, $K$ Y. De Sole G: Nmmel, J. Soumbey Alley, E: Unnasch, T. R; Onchocerca volvolus: DNA probe classification correlates with epidemiologic patterns of blindness $\mathrm{J}$. Inf. Dis 1992. 165:964 - 968.

1. McMahon, J. E: Savas, I. M. Rudson G. M.: woód B. R. Epidemiological Studies of onchocerciasis of forest villages of Sierra Leone Trop. Med. Parasitol, 1988: 39: $251-259$.

12. World Health Organisation: Methods of community Diagnosis of Onchocerciasis to guide ivermectin based control in Africa. W.H.O Geneva.

13. Robert 1: Anderson D. B.: Thomas A. A. Mackae $A:$ Onchocerciasis prevalence of microfilaria and other manifestation in a village of Cameroom Am. J. trop. Med. Hyg. 1975, 24:66-7. 